\title{
Helicobacter pylori adherence to gastric epithelial cells: a role for non-adhesin virulence genes
}

\author{
ZUN-WU ZHANG, NICK DORRELL*, BRENDAN W. WREN*, MICHAEL J. G. FARTHING $\dagger$ \\ Division of Surgery, Bristol Royal Infirmary, University of Bristol, Bristol, * Department of Infectious and \\ Tropical Diseases, London School of Hygiene and Tropical Medicine, London and †Faculty of Medicine, \\ University of Glasgow, Glasgow, UK
}

Helicobacter pylori is a major aetiological agent in gastroduodenal disorders and adherence of the bacteria to the gastric mucosa is one of the initial stages of infection. Although a number of specific adhesins has been identified, other $\boldsymbol{H}$. pylori virulence factors may play a role in adherence to gastric epithelial cells directly or through interaction with other adhesins. This study assessed the effect of $16 \mathrm{H}$. pylori virulence factors on the adherence of the bacteria to gastric AGS cells and on gastric epithelial cell cycle distribution. Defined isogenic $H$. pylori SS1 mutants were used. After coincubation of gastric AGS cells and bacteria, adherence of $H$. pylori to AGS cells was visualised by immunofluorescence microscopy and quantified by flow cytometry. Cell cycle phase distribution was analysed by flow cytometry with propidium iodide staining. Mutants were tested for their ability to adhere to AGS cells and compared with the wild-type SS1 strain. Mutations in genes in the cag pathogenicity island showed that cagP and $\operatorname{cag} E$ mutants adhered less than the wild-type strain to AGS cells, whereas a cagF mutant showed no reduction in adherence. Mutations in genes involved in flagellar biosynthesis showed that the adherence ability of $\mathrm{fliQ}$, fliM and fliS mutants was reduced, but a $f l h B$ mutant possessed wild-type levels of adherence. Mutations in genes coding for the urease (ureB) and phospholipase (pldA) enzymes did not affect adherence, but mutation of the $\operatorname{tly} A$ gene encoding an $H$. pylori haemolysin resulted in a reduced adherence. A fli $Q$ mutant, with reduced adherence to AGS cells, was less able to induce AGS cell apoptosis than SS1. The ability to induce $G_{0} G_{1}$ cell cycle arrest was also abolished in the $f l i Q$ mutant. However, an increased cell number in $S$ phase was observed when AGS cells were exposed to the fliQ mutant compared with SS1, suggesting that unattached bacteria may still be able to stimulate cell proliferation. In addition to known adhesins, other bacterial virulence factors such as CagE, CagP, FliQ, FliM, FliS and TlyA appear to play a role in $H$. pylori adherence to gastric epithelial cells. Mutations in these genes may affect $H$. pylori pathogenicity by reducing either the ability of the bacteria to attach to gastric epithelial cells or the intensity of bacteriahost cell interactions.

\section{Introduction}

Chronic infection with Helicobacter pylori, the main cause of chronic gastritis, results in various disease outcomes including peptic ulceration, gastric adenocarcinoma and gastric lymphoma [1]. The bacterium colonises the gastric mucosa by adhering to and penetrating the mucus layer lining the gastric epi-

Received 31 July 2001; revised version received 3 Dec. 2001; accepted 7 Dec. 2001.

Corresponding author: Dr Z.-W. Zhang (e-mail: z.w.zhang@ bristol.ac.uk). thelium [2]. Colonisation of the gastric mucous layer protects the bacteria from the extreme acidity of the gastric lumen and displacement from the stomach by forces such as those generated by peristalsis and gastric emptying. The majority of the colonising bacteria remain in the gastric mucous layer, but some adhere to the gastric epithelial cells. The clinical significance of the host-pathogen interactions that follow attachment of $H$. pylori to human gastric cells remains to be fully elucidated. It is considered unlikely that chronic infection with $H$. pylori could occur in the absence of adhesin-host cell interactions [3]. Therefore, adherence of the bacteria to the gastric mucosa is 
one of the initial steps of $H$. pylori infection and is an important virulence factor.

Bacterial surface structures play an important role in determining the mode of interaction of individual bacteria with other bacteria and with other factors in their immediate surroundings. H. pylori has evolved a repertoire of interactive surface molecules that enable the bacteria to adhere to human gastric epithelial cells and phagocytic cells via adhesins interacting with hostcell receptors. Many different $H$. pylori adhesins have been identified [4], implying that adherence is a multifactorial process. However, there is no consensus as to which adhesins are most important in vivo, or whether adhesin(s) and receptor(s) for the $H$. pylori-epithelial cell interactions are similar to the $H$. pylori-phagocytic cell interactions. Furthermore, although adhesins are a group of bacterial surface molecules, their adhesive functions may be inhibited or enhanced by other bacterial virulence factors during the processes of adhesin synthesis, transportation, secretion and activation. The real challenge in this post-genomic era is not only to study known adhesins to determine which are important in vivo, but also to identify other bacterial factors which may have an effect on $H$. pylori adherence.

At least five different $H$. pylori adhesins have been described [4]. One group of putative adhesins is the $H$. pylori outer-membrane protein (Hop) family, represented in the strain 26695 genome sequence by 32 members [5]. Three previously identified $H$. pylori adhesins belong to the Hop family [6-8]: AlpA and AlpB, which may act as adhesins and recognise different receptors on the gastric epithelial cell surface, and the BabA adhesin, which mediates attachment to the blood group antigen Lewis ${ }^{b}\left(\mathrm{Le}^{\mathrm{b}}\right)$ [9]. It is suggested that other members of the Hop family may also act as adhesins. Recently, Namavar et al. [10] identified a $16-\mathrm{kDa}$ surface protein that adhered to oligosaccharide ligands such as sulphated Lewis ${ }^{\mathrm{a}}\left(\mathrm{Le}^{\mathrm{a}}\right)$ antigens present on mucin glycoproteins. Tomb et al. [5] showed that the Hop genes have highly homologous domains at the $5^{\prime}$ and $3^{\prime}$ ends. This feature suggests the possibility of recombination and hence an increase in antigenic variation. One of these genes, hopZ, has been characterised recently. A hopZ mutant showed significantly reduced binding to human gastric epithelial cells compared with the wild-type strain ATCC 43504 [11].

This study assessed the effect of mutations in $16 \mathrm{H}$. pylori virulence genes not previously associated as adhesins on bacterial adherence to gastric AGS cells. All the genes studied can be defined as virulence determinants, either through previous $H$. pylori studies or by their similarity to virulence genes in other bacteria. To further assess the importance of bacterial adherence on $H$. pylori pathogenicity, the effect of some of these mutants on AGS cell cycle progression was also investigated.

\section{Materials and methods}

\section{Construction of defined isogenic H. pylori mutants}

H. pylori wild-type strain SS1 was used in this study [12]. Defined isogenic $H$. pylori SS1 mutants were constructed as described previously [13]. Briefly, specific amplifying primers for each gene were designed from the $H$. pylori 26695 genome sequence. The resulting PCR products were amplified from $H$. pylori 26695 chromosomal DNA and cloned into pUC19. A defined deletion and unique $B g I I I$ site were introduced into each of the cloned genes by inverse PCR mutagenesis $[14,15]$. A kanamycin resistance gene was cloned into the unique BgIII site and these constructs were introduced into the SS1 wild-type strain by electroporation [16]. Double-crossover mutants were selected and screened as described previously [13]. The H. pylori wild-type strain and the mutant strains used are listed in Table 1.

\section{Cell culture and growth of $H$. pylori strains}

Gastric AGS cells, derived from human gastric carcinomas, were grown in culture medium consisting

Table 1. H. pylori SS1 and its isogenic mutants

\begin{tabular}{llcl}
\hline Code no. & Gene & HP no. & Function \\
\hline SS1 & Wild-type & $\ldots$ & $\ldots$ \\
ND1 & cagP & 0536 & cag pathogenicity island; function unknown \\
ND4 & cagE & 0544 & cag pathogenicity island; IL-8 induction \\
ND8 & cagF & 0543 & cag pathogenicity island; function unknown \\
ND3 & ureB & 0072 & Urease $\beta$-subunit (urea amidohydrolase) \\
ND5 & pldA & 0499 & Phospholipase [13] \\
ND6 & fliI & 1420 & Flagellar export protein (ATP synthase) [17, 18] \\
SF1 & fliG & 0352 & Flagellar motor switch protein [19] \\
SF3 & fliQ & 1419 & Flagellar biosynthetic protein [19, 20] \\
SF4 & $f l i M$ & 1031 & Flagellar motor switch protein \\
SF5 & $f l h B$ & 1575 & Flagellar biosynthetic protein [19, 20] \\
MW1 & $f l i S$ & 0753 & Flagellar biosynthetic protein [19] \\
MW2 & fliF & 0351 & Flagellar basal-body M-ring protein [19] \\
EA2 & feoB & 0687 & Iron (II) transport protein, ferrous binding protein [21] \\
RS1 & cheY1 & 1067 & Chemotaxis response regulator [22] \\
SF6 & che $A Y 2$ & 0392 & Chemotaxis histidine kinase [22] \\
RS7 & $t l y A$ & 1086 & Haemolysin [23] \\
\hline
\end{tabular}


of RPMI 1640 medium, fetal calf serum (FCS; SigmaAldrich, Poole) $10 \%$, penicillin $100 \mathrm{IU} / \mathrm{ml}$, streptomycin $100 \mu \mathrm{g} / \mathrm{ml}$ and $2 \mathrm{mM} \mathrm{L}$-glutamine. The cells were maintained in a humidified atmosphere of $\mathrm{CO}_{2}$ $5 \%$ and air $95 \%$ at $37^{\circ} \mathrm{C}$. All the reagents and medium were purchased from GibcoBRL (Paisley).

H. pylori strains were stored at $-80^{\circ} \mathrm{C}$ in Brain Heart Infusion (BHI) broth (Oxoid) containing glycerol 15\% $\mathrm{v} / \mathrm{v}$ and FCS $10 \% \mathrm{v} / \mathrm{v}$. Strains were grown in BHI broth supplemented with FCS $10 \% \mathrm{v} / \mathrm{v}$ or on Helicobacter selective agar (DENT), consisting of Blood Agar Base No. 2 (Oxoid) supplemented with lysed defibrinated horse blood (TCS Microbiology, Botolph Claydon) $7 \% \mathrm{v} / \mathrm{v}$ and DENT selective supplement (Oxoid), in a micro-aerobic atmosphere at $37^{\circ} \mathrm{C}$. For the adherence assay, overnight broth cultures were resuspended in phosphate-buffered saline (PBS) to a final concentration of $5 \times 10^{8} \mathrm{cfu} / \mathrm{ml}$ $\left(\mathrm{OD}_{450} \approx 1.0\right)$. For the cell cycle analysis, the bacteria were grown on Columbia Blood Agar containing horse blood 5\% (Oxoid) for $48 \mathrm{~h}$ under micro-aerobic conditions.

\section{H. pylori adherence assay}

The adherence assay was performed as described previously [24]. Gastric AGS cells $\left(5 \times 10^{6}\right.$ cells) and H. pylori $\left(5 \times 10^{8} \mathrm{cfu}\right)$ were incubated at $37^{\circ} \mathrm{C}$ for $1 \mathrm{~h}$ with agitation $(150 \mathrm{rpm})$. Non-adherent bacteria were removed by centrifugation with $10 \mathrm{ml}$ of sucrose $15 \%$ w/v solution. Cells were washed once with PBS and then incubated with a 1 in 5 dilution of polyclonal antiH. pylori antibody (SkyTek Laboratories, Logan, USA) on ice for $30 \mathrm{~min}$. After washing with $15 \mathrm{ml}$ of PBS, the cells were incubated for an additional $30 \mathrm{~min}$ on ice in a 1 in 20 dilution of fluorescein isothiocyanate (FITC)-conjugated goat anti-rabbit IgG (SigmaAldrich). The cells were washed and resuspended in $1 \mathrm{ml}$ of formaldehyde $1 \%$. Before flow cytometric analysis, the adherence of the bacteria to AGS cells was visualised by fluorescence microscopy. A FACScan flow cytometer (Becton Dickinson, San Jose, CA, USA) was used to measure bacteria adhering to AGS cells. By using a dot-plot display of forward light scatter and side $\left(90^{\circ}\right)$ light scatter, the machine was gated to include single cells and to exclude cell debris and unbound bacteria. Fluorescence data were acquired in log-model on a 256-channel scale by an analysis of 10000 individual cells. The results were expressed as the positive percentage of fluorescent cells calculated from fluorescence frequency distribution histograms. The threshold of cells without adherent bacteria was established for each experiment, the cells being stained with the two-step FITC-conjugated H. pylori antibody method described above. All experiments were repeated at least three times.
Flow cytometric analysis for gastric epithelial apoptosis and cell cycle phase distribution

Subconfluent AGS cells were incubated with or without H. pylori (bacteria:cell ratio 100:1) for $48 \mathrm{~h}$. The effect of $H$. pylori on gastric epithelial cell cycle phase distribution was assessed by flow cytometry as described previously [25]. Briefly, a pool of detached and adherent cells was washed in PBS, then the cells were fixed in ice-cold ethanol $70 \%$ overnight. The cell pellets were resuspended in $1 \mathrm{ml}$ of a solution containing ribonuclease (Sigma-Aldrich) $200 \mu \mathrm{g} / \mathrm{ml}$ and propidium iodide (Sigma-Aldrich) $50 \mu \mathrm{g} / \mathrm{ml}$ for $60 \mathrm{~min}$ at $37^{\circ} \mathrm{C}$. Cell cycle analysis was performed on a FACScan flow cytometer equipped with FACStation ${ }^{\mathrm{TM}}$ and CellQuest software (Becton Dickinson Immunocytometry Systems, Oxford). Debris was eliminated from the analysis with a forward angle light scatter threshold. Cell doublets and clumps were gated out of the analysis with a dot-plot display of area and width; 10000 cells were analysed for each sample and the apoptotic cells were considered to constitute the sub- $\mathrm{G}_{1}$ cell population. All experiments were repeated at least three times.

\section{Statistical analysis}

Any significance in differences between two data sets was determined by the Student's $t$ test and by singlefactor ANOVA for more than two data sets. $p$ values $<0.05$ were considered significant in all analyses.

\section{Results}

Effect of $H$. pylori strains on bacterial adherence to gastric AGS cells

The morphology and growth rate of the 16 isogenic SS1 mutants were assessed and showed no significant differences when compared to the wild-type strain. The ability of these mutants to adhere to cultured human AGS cells was analysed (Table 2). The results are presented as a percentage figure calculated from the number of AGS cells adhered to by H. pylori strains and the total number of AGS cells analysed by flow cytometry. Statistical analysis was performed on each data set and a reduction in the ability of an individual mutant to adhere to AGS cells was deemed significant if $\mathrm{p}<0.05$. Reduced adherence was observed with mutations of the cagP, cagE, fliQ, fliM, fliS and tlyA genes. The reduction in adherence to AGS cells is obviously not a result of the introduction of the kanamycin resistance cassette during mutagenesis, as many $H$. pylori SS1 mutants showed wild-type levels of adherence.

\section{Effect of H. pylori strains on gastric AGS cell apoptosis and cell cycle progression}

To examine the effect of $H$. pylori adherence on the pathogenicity of the bacterium, gastric AGS cell cycle 
Table 2. Bacterial surface structures and $H$. pylori adherence to gastric AGS cells

\begin{tabular}{lllc}
\hline Code no. & Gene & $\begin{array}{c}\text { Mean }(\mathrm{SD}) \\
\text { adherence }\end{array}$ & p value \\
\hline SS1 & Wild-type & $92.8(2.6)$ & $\ldots$ \\
ND1 & cagP & $75.7(17.7)$ & 0.01 \\
ND4 & cagE & $52.1(9.7)$ & $<0.0001$ \\
ND8 & cagF & $92.3(7.8)$ & 0.9 \\
ND3 & ureB & $95.6(2.6)$ & 0.3 \\
ND5 & pldA & $92.0(1.3)$ & 0.1 \\
ND6 & fli & $99.3(0.5)$ & 0.1 \\
SF1 & fli & $96.9(4)$ & 0.38 \\
SF3 & fliQ & $62.8(13.2)$ & 0.0001 \\
SF4 & fliM & $58.8(5.6)$ & $<0.0001$ \\
SF5 & flhB & $96.8(3.7)$ & 0.1 \\
MW1 & fliS & $58(5.3)$ & $<0.0001$ \\
MW2 & fliF & $96.6(1.2)$ & 0.3 \\
EA2 & feoB & $91.6(4.5)$ & 0.8 \\
RS1 & cheY1 & $83.5(15.1)$ & 0.1 \\
SF6 & cheAY2 & $95.1(6.4)$ & 0.4 \\
RS7 & tlyA & $71.4(7.5)$ & $<0.0001$ \\
\hline
\end{tabular}

distribution was further analysed after exposure to the H. pylori SS1 wild-type strain and ureB, pldA and fliQ isogenic mutants. A significant induction of AGS cell apoptosis was observed by incubating either with the wild-type strain or its mutants $(\mathrm{p}=0.002,0.0003$, 0.0007 and 0.00001 , respectively), but the rates induced by the mutants were markedly lower than their parent strain SS1 $(p=0.007,0.01$ and 0.01, respectively) (Fig. 1). There were no significant differences in the induction of AGS cell apoptosis among the three mutants. Analysis of cell cycle phase distribution of surviving cells indicated that cells exposed to strain SS1 showed significant inhibition of cell cycle progression with $62.8 \pm 1 \%$ of live cells arrested in $\mathrm{G}_{0} \mathrm{G}_{1}$ phases (Fig. 2). However, the ability to induce $\mathrm{G}_{0} \mathrm{G}_{1}$ cell cycle arrest was abolished in all three mutants $(\mathrm{p}=0.0008,0.0004$ and 0.001 , respectively). Interestingly, the fliQ mutant, which has a

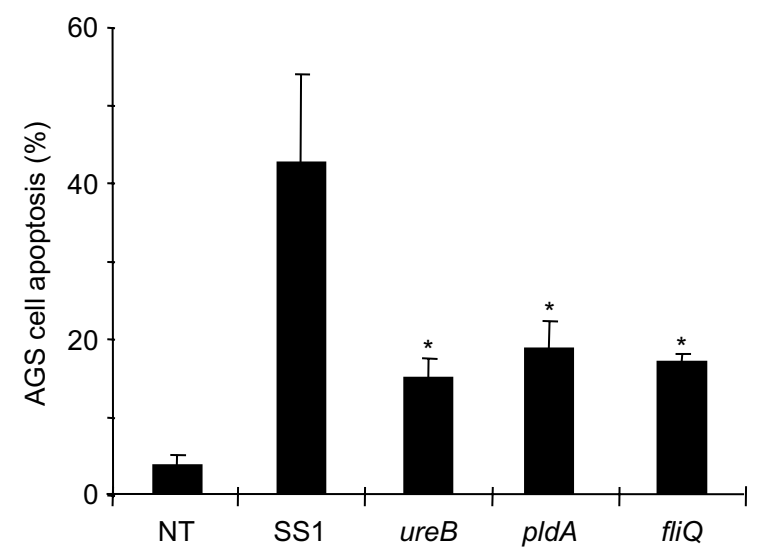

Fig. 1. H. pylori-induced gastric AGS cell apoptosis. Subconfluent AGS cells were incubated in the presence or absence of $\mathrm{H}$. pylori for $48 \mathrm{~h}$. The induction of AGS cell apoptosis was assessed by flow cytometry with propidium iodide staining. The results are expressed as percentage of total cells analysed and represent an average of three or more experiments. NT, untreated control. ${ }^{*} \mathrm{p}<0.01$. reduced adherence to gastric cells, showed a marked increase in cell numbers in $\mathrm{S}$ phase compared with untreated control cells $(\mathrm{p}<0.0001)$ and the wild-type strain $(\mathrm{p}<0.001)$. The ureB and pldA mutants showed no obvious effect on the cell cycle phase distribution of surviving AGS cells when compared to untreated control cells $(p=0.2$ and 0.1 , respectively) and to the wild-type strain $(\mathrm{p}=0.2$ and 0.1 , respectively).

\section{Discussion}

Clinical isolates of $H$. pylori are known to differ in virulence and those from individuals with peptic ulcers are mostly type I strains which express both VacA and CagA [26]. The $\operatorname{cag} A$ gene is a marker for a large $40-\mathrm{kb}$ locus containing $>40$ genes, termed the cag pathogenicity island (cag PAI), and the majority of these genes encode membrane-associated proteins with features similar to other bacterial secretion systems, particularly the type IV system epitomised by Bordetella pertussis toxin secretion [27-29]. A cagE mutant induced only mild inflammation in Mongolian gerbils, whereas the wild-type strain and vacA mutants induced more severe gastritis [30]. Mutation of cagE abolishes the ability of $H$. pylori to induce the cytokine interleukin-8 (IL-8), a neutrophil chemotactic factor, in Kato-3 cells [27, 29, 31,32]. Adherence has been shown to play a role in the induction of $H$. pyloriassociated IL-8 secretion [33]. The present study has clearly shown that mutation of $c a g E$ markedly reduced the adherence of $H$. pylori to gastric AGS cells. This finding suggests that the inability of a $\operatorname{cag} E$ mutant to stimulate IL-8 induction may be partly due to the loss of adherence capacity to gastric epithelial cells. A recent study has also found that a $\operatorname{cag} E$ mutant failed to colonise both $\mathrm{C} 57 \mathrm{BL} / 6 \mathrm{j}$ and $\mathrm{BALB} / \mathrm{c}$ mice [34]. The present study also found that a cagP mutant had reduced adherence to gastric AGS cells, but not a $\operatorname{cag} F$ mutant. The function of $\mathrm{CagP}$ and $\mathrm{CagF}$ has yet to be defined. Although the reasons leading to the reduced adherence capacity in these mutants remain unclear, data from the present study suggest that some genes in the cag PAI play a role in $H$. pylori adherence to gastric epithelial cells.

H. pylori motility is essential for colonisation [35]. Motility enables the bacterium to spread into the viscous mucous layer covering the gastric epithelium. At least 40 proteins in the $H$. pylori 26695 genome appear to be involved in the regulation, secretion and assembly of the flagellar architecture [5]. In Salmonella enterica serovar Typhimurium, the first structure in flagellar assembly is the MS ring (FliF). The next structure assembled is the $\mathrm{C}$ ring which contains the switch proteins, FliG, FliM and FliN. This is followed by rod assembly for which several proteins, including FliI, FliQ and FlhB, are required in addition to the rod structural proteins $[36,37]$. These proteins, believed to be located at the cytoplasmic side of the basal body 


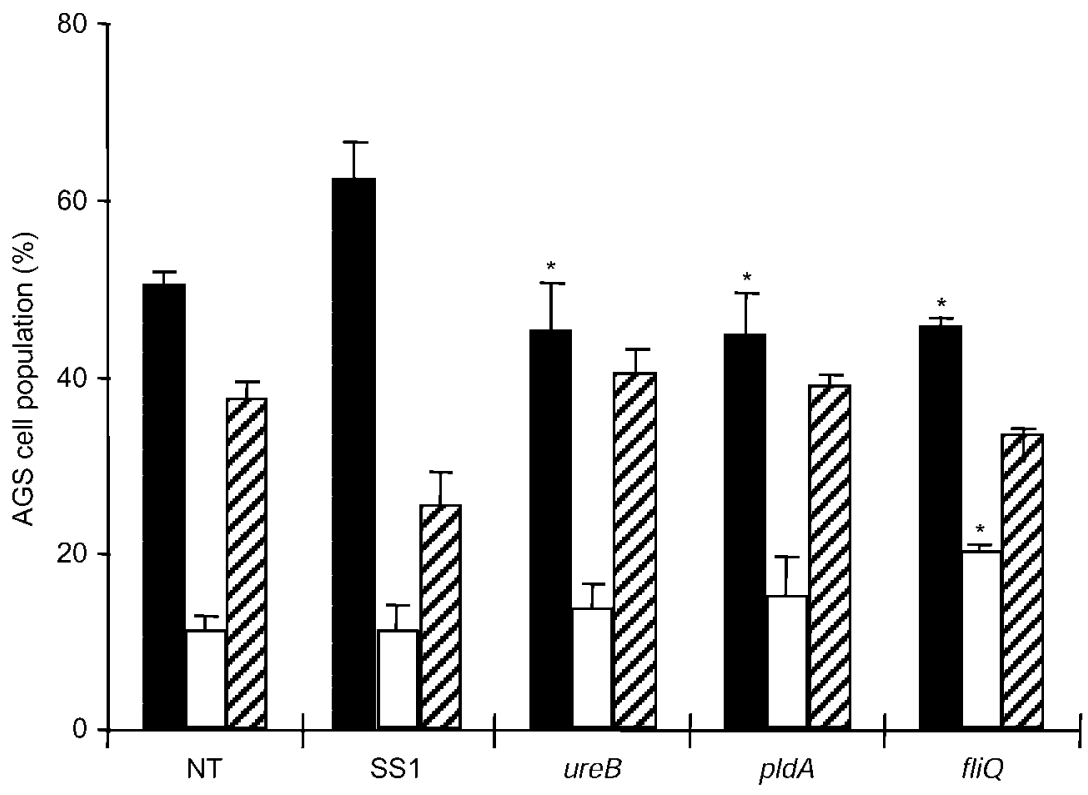

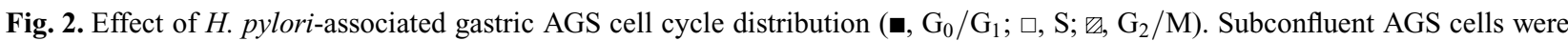
incubated in the presence or absence of $H$. pylori for $48 \mathrm{~h}$. The effect of $H$. pylori on AGS cell cycle phase distribution was assessed by flow cytometry with propidium iodide staining. The results are expressed as percentage of total cells analysed and represent an average of three or more experiments. NT, untreated control. ${ }^{*} \mathrm{p}<0.001$.

near to the switch [37], are thought to be components of the flagellum-specific export apparatus, exhibiting pronounced amino acid similarities with proteins involved in export of virulence factors [36]. FliS, required for efficient elongation of the filament in $S$. Typhimurium, is thought to be a cytoplasmic chaperone for flagellin export [37]. Factors responsible for colonisation may not affect the direct adherence to the cells, as adhesion to and colonisation of the gastric mucosa are separate stages of $H$. pylori infection $[19,20]$. This is supported by data from the present study which show that some of the non-motile mutants are still able to adhere to AGS cells. However, the fliQ, $f i M$ and $f i S$ mutants all showed a reduced adherence to gastric epithelial cells. This may be due to the fact that these mutants are defective in some adherence pathway. For example, FliQ is probably involved in a type III export pathway in $H$. pylori $[19,20]$. Therefore, the reduced level of adherence may underline the inability of the $f l i Q$ mutant to export a protein with a role in adherence. In contrast, mutants such as $f h B$ or $f l i$, which do not appear to be involved in the type III export pathway, showed wild-type levels of adherence. Mutations in genes involved in the regulation of chemotaxis (cheAY2 and cheYl) did not appear to affect adherence to gastric epithelial cells.

Like other pathogens, H. pylori possesses iron-scavenging systems for survival under the low iron conditions encountered in the human host [4]. Genomic analysis suggests that $H$. pylori has several systems for iron uptake [5]. One system for iron uptake present in $H$. pylori appears to be similar to the ferrous ( $f e o$ ) iron uptake system present in Escherichia coli. The feoAB operon encodes proteins which contribute significantly to the iron supply of $E$. coli cells under anaerobic conditions [38]. An feoB-like gene (HP0687), coding for a putative cytoplasmic protein with homology to ATPase, was identified in $\mathrm{H}$. pylori, whereas no feoA orthologue seems to be present. Although FeoB has been shown to be important in both $\mathrm{Fe}^{2+}$ and $\mathrm{Fe}^{3+}$ transport [21,39], the data from the present study did not support a role for this protein in H. pylori adherence.

One of the notable features of $H$. pylori grown on unlysed blood agar plates is haemolytic activity and it has been suggested that haemolysins may affect the biological activity of bacterial adhesins $[40,41]$. It is known that $E$. coli haemolysins, by interacting with bacterial adhesins, can accelerate and enhance the rate of phagocytosis of bacteria by neutrophils and also increase the release of histamine and leukotriene from inflammatory cells [42]. Mutation of the gene encoding the H. pylori haemolysin TlyA significantly reduced the adherence of the organism to AGS cells. This suggests that there may be some interaction between TlyA and H. pylori adhesins, although the underlying mechanisms remain unclear. In contrast, mutation of the gene encoding the $H$. pylori phospholipase PldA, which also results in reduced haemolytic activity [13], showed a similar level of adherence to the wild-type strain. This suggests that PldA, whilst possessing haemolytic activity, has no role in adherence.

Bacterial adherence to host cells has been shown to be an important factor in the induction of cell cycle changes [43]. To examine whether the changes observed in $H$. pylori adherence to gastric epithelial cells have any effect on bacteria-associated cell damage, the 
present study assessed $H$. pylori-induced gastric epithelial cell cycle changes after exposure to SS1 and three mutants: ureB, pldA and fliQ. Both UreB and PldA are important virulence factors. Mutations in these genes produced $u r e B$ and pldA mutants with normal levels of adherence to AGS cells, whereas a fliQ mutant showed a markedly decreased adherence ability to AGS cells. Apoptosis is a prominent feature of $\mathrm{H}$. pylori-induced epithelial cell damage. Many factors are responsible for the induction of $\mathrm{H}$. pyloriassociated gastric epithelial cell apoptosis [44]. The data from the present study further confirm that phospholipase and urease activities plus bacterial adherence to host cells are important factors in the induction of apoptosis.

H. pylori possesses several different phospholipase (PL) activities, such as $\mathrm{PLA}_{1}, \mathrm{PLA}_{2}$ and PLC [45]. The main activities of these PLs are thought to be the degradation of the phospholipid components of the mucosal barrier and normal phospholipid bilayer of the epithelial cell membrane [46]; but it may also influence the synthesis of prostaglandin [47]. Phospholipids constitute c. $20 \%$ of the dry weight of the human gastric mucus and are believed to be important in generating a hydrophobic barrier and maintaining normal cell functions. It has been reported that mucosal hydrophobicity is reduced in $H$. pylori-positive patients with duodenal ulcer compared with those having gastritis only [48]. The significantly diminished induction of apoptosis and cell cycle arrest by the pldA mutant suggests that $H$. pylori phospholipase activity may play an important role in $H$. pylori-associated gastric epithelial cell damage.

H. pylori produces high levels of urease, which makes up about $6 \%$ of the total bacterial protein [49]. This enzyme breaks down urea into ammonia and carbon dioxide, providing an acid-neutralising cloud of ammonia that could protect the bacterium from gastric acidity [50]. It has become increasingly clear that this is not the only function of urease in the physiology of H. pylori [51]. Although previous studies have suggested that the urease activity of $H$. pylori may be important in bacterial colonisation $[4,13,52,53]$, this study did not find a role for $\mathrm{UreB}$ in adherence to gastric epithelial cells. This may be because factors responsible for colonisation may not affect the direct adherence to the cells as adhesion to and colonisation of the gastric mucosa are separate stages of $H$. pylori infection [37]. However, a ureB mutant showed a reduced ability in inducing AGS cell apoptosis and an inhibited induction of $\mathrm{G}_{0} \mathrm{G}_{1}$ cell cycle arrest. These data further characterise the role of urease activity in H. pylori pathogenesis. Significant reductions in the levels of apoptosis and AGS cell cycle arrest were observed after exposure to the fliQ mutant, which has a significantly decreased adherence to AGS cells compared with the wild-type strain. Because the fliQ mutant still possesses intact $H$. pylori virulence factors, such as UreB and PldA, the reduced abilities to induce apoptosis and cell cycle arrest further demonstrate the importance of $H$. pylori adherence. Similarly, the ability of $H$. pylori to induce $\mathrm{G}_{0} \mathrm{G}_{1}$ cell cycle arrest was abolished in all three mutants. This further suggests that bacterial virulence factors and bacterial adherence are both important determinants in $H$. pylori-induced cell cycle changes. Also, cells coincubated with the $f l i Q$ mutant showed a significantly increased cell number in the $\mathrm{S}$ phase of cell cycle compared with cells exposed to the wild-type strain and untreated control cells, suggesting that exposure to the fliQ mutant may stimulate AGS cell proliferation. This may represent the effect of unattached bacteria on gastric epithelial cells. Although a proportion of $H$. pylori adhere to the gastric epithelial cells of gastric tissue, the majority of the organisms in infected patients remain in the mucus layer [54]. Therefore, investigation of the behaviour of unattached bacteria in the stomach may be of clinical importance. The enhanced AGS cell number in $\mathrm{S}$ phase following exposure to the fliQ mutant suggests that $H$. pylori may stimulate gastric epithelial cell proliferation, even without adherence to the epithelial cells. Further work is required to substantiate this hypothesis.

In summary, this study assessed the adherence of 16 SS1 isogenic mutants to gastric epithelial cells by fluorescence microscopy and flow cytometry. Mutations in genes in the cag PAI showed that $\operatorname{cag} P$ and $\operatorname{cag} E$ had significantly reduced adhesion, whereas a $\operatorname{cag} F$ mutant showed no difference compared to SS1. Mutation of $f l i Q$, fliM or $f l i S$ genes significantly reduced the adherence of $H$. pylori to AGS cells compared with the wild-type strain. Mutations of the $p l d A$, ureB and $f e o B$ genes did not affect adherence, but a tlyA mutant showed significantly reduced adherence to AGS cells. Induction of AGS cell apoptosis was markedly reduced in cells exposed to the pldA, ure $B$ and $f l i Q$ mutants. Analysis of cell cycle phase distribution of surviving cells showed that mutations in fli $Q$, ureB or $p l d A$ reduced the ability of the bacterium to induce AGS cell cycle arrest. Apart from adhesins, many other bacterial virulence factors such as CagE, CagP, FliQ, FliM, FliS and TlyA appear to play a role in $H$. pylori adherence to gastric epithelial cells. Mutation of the encoding genes may not only influence bacterial adherence, but may also have an effect on the pathogenicity of the organism.

\section{References}

1. Williams MP, Pounder RE. Helicobacter pylori: from the benign to the malignant. Am J Gastroenterol 1999; 94(II Suppl): S11-S16.

2. Blaser MJ, Kirschner D. Dynamics of Helicobacter pylori colonization in relation to the host response. Proc Natl Acad Sci USA 1999; 96: 8359-8364.

3. Evans DJ, Evans DG. Helicobacter pylori adhesins: review and perspectives. Helicobacter 2000; 5: 183-195.

4. Labigne A, de Reuse H. Determinants of Helicobacter pylori 
pathogenicity. Infect Agents Dis 1996; 5: 191-202.

5. Tomb J-F, White O, Kerlavage AR et al. The complete genome sequence of the gastric pathogen Helicobacter pylori. Nature 1997; 388: 539-547.

6. Borén T, Falk P, Roth KA, Larson G, Normark S. Attachment of Helicobacter pylori to human gastric epithelium mediated by blood group antigens. Science 1993; 262: 1892-1895.

7. Odenbreit S, Till M, Hofreuter D, Faller G, Haas R. Genetic and functional characterization of the alpAB gene locus essential for the adhesion of Helicobacter pylori to human gastric tissue. Mol Microbiol 1999; 31: 1537-1548.

8. Odenbreit S, Till M, Haas R. Optimized BlaM-transposon shuttle mutagenesis of Helicobacter pylori allows the identification of novel genetic loci involved in bacterial virulence. Mol Microbiol 1996; 20: 361-373.

9. Ilver D, Arnqvist A, Ögren J et al. Helicobacter pylori adhesin binding fucosylated histo-blood group antigens revealed by retagging. Science 1998; 279: 373-377.

10. Namavar F, Sparrius M, Veerman ECI, Appelmelk BJ, Vandenbroucke-Grauls CMJE. Neutrophil-activating protein mediates adhesion of Helicobacter pylori to sulfated carbohydrates on high-molecular-weight salivary mucin. Infect Immun 1998; 66: 444-447.

11. Peck B, Ortkamp M, Diehl KD, Hundt E, Knapp B. Conservation, localization and expression of HopZ, a protein involved in adhesion of Helicobacter pylori. Nucleic Acid Res 1999; 27: 3325-3333

12. Lee A, O'Rourke J, Corazon De Ungria M, Robertson B, Daskalopoulos G, Dixon MF. A standardized mouse model of Helicobacter pylori infection: introducing the Sydney strain. Gastroenterology 1997; 112: 1386-1397.

13. Dorrell N, Martino MC, Stabler RA et al. Characterization of Helicobacter pylori PldA, a phospholipase with a role in colonization of the gastric mucosa. Gastroenterology 1999; 117: $1098-1104$.

14. Dorrell N, Gyselman VG, Foynes S, Li SR, Wren BW. Improved efficiency of inverse PCR mutagenesis. Biotechniques 1996; 21: 604, 606, 608.

15. Wren BW, Henderson J, Ketley JM. A PCR-based strategy for the rapid construction of defined bacterial deletion mutants. Biotechniques 1994; 16: 994-996.

16. Segal ED, Tompkins LS. Transformation of Helicobacter pylori by electroporation. Biotechniques 1993; 14: 225-226.

17. Dunn BE, Altmann M, Campbell GP. Adherence of Helicobacter pylori to gastric carcinoma cells: analysis by flow cytometry. Rev Infect Dis 1991; 13 Suppl 8: S657-S664.

18. Ormerod MG. Analysis of DNA - general methods. In: Ormeron MG (ed) Flow cytometry: a practical approach, 2nd edn. Oxford, Oxford University Press. 1994: 119-135.

19. Jenks PJ, Foynes S, Ward SJ, Constantinidou C, Penn CW, Wren BW. A flagellar-specific ATPase (FliI) is necessary for flagellar export in Helicobacter pylori. FEMS Microbiol Lett 1997; 152: 205-211.

20. Porwollik S, Noonan B, O'Toole PW. Molecular characterization of a flagellar export locus of Helicobacter pylori. Infect Immun 1999; 67: 2060-2070.

21. Allan E, Dorrell N, Foynes S, Anyim M, Wren BW. Mutational analysis of genes encoding the early flagellar components of Helicobacter pylori: evidence for transcriptional regulation of flagellin A biosynthesis. J Bacteriol 2000; 182: 5274-5277.

22. Velayudhan J, Hughes NJ, McColm AA et al. Iron acquisition and virulence in Helicobacter pylori: a major role for $\mathrm{FeoB}$, a high-affinity ferrous iron transporter. Mol Microbiol 2000; 37: 274-286.

23. Foynes S, Dorrell N, Ward SJ et al. Helicobacter pylori possesses two Che $\mathrm{Y}$ response regulators and a histidine kinase sensor, CheA, which are essential for chemotaxis and colonization of the gastric mucosa. Infect Immun 2000; 68: 2016-2023.

24. Martino MC, Stabler RA, Zhang ZW, Farthing MJG, Wren BW, Dorrell N. The Helicobacter pylori pore-forming cytolysin orthologue TlyA possesses in vitro haemolytic activity and has a role in colonization of the gastric mucosa. Infect Immun 2001; 69: 1697-1703

25. Xiang Z, Censini S, Bayeli PF et al. Analysis of expression of CagA and VacA virulence factors in 43 strains of Helicobacter pylori reveals that clinical isolates can be divided into two major types and that CagA is not necessary for expression of the vacuolating cytotoxin. Infect Immun 1995; 63: 94-98.
26. Censini S, Lange C, Xiang Z et al. cag, a pathogenicity island of Helicobacter pylori, encodes type I-specific and diseaseassociated virulence factors. Proc Natl Acad Sci USA 1996; 93: $14648-14653$.

27. Naumann M, Wessler S, Bartsch $\mathrm{C}$ et al. Activation of activator protein 1 and stress response kinases in epithelial cells colonized by Helicobacter pylori encoding the cag pathogenicity island. J Biol Chem 1999; 274: 31655-31662.

28. Odenbreit S, Püls J, Sedlmaier B, Gerland E, Fischer W, Haas R. Translocation of Helicobacter pylori CagA into gastric epithelial cells by type IV secretion. Science 2000; 287: $1497-$ 1500 .

29. Ogura K, Maeda S, Nakao M et al. Virulence factors of Helicobacter pylori responsible for gastric diseases in Mongolian gerbil. $J$ Exp Med 2000; 192: 1601-1609.

30. Tummuru MK, Sharma SA, Blaser MJ. Helicobacter pylori picB, a homologue of the Bordetella pertussis toxin secretion protein, is required for induction of IL-8 in gastric epithelial cells. Mol Microbiol 1995; 18: 867-876.

31. Segal ED, Lange C, Covacci A, Tompkins LS, Falkow S. Induction of host signal transduction pathways by Helicobacter pylori. Proc Natl Acad Sci USA 1997; 94: 7595-7599.

32. Rieder G, Hatz RA, Moran AP, Walz A, Stolte M, Enders G Role of adherence in interleukin- 8 induction in Helicobacter pylori-associated gastritis. Infect Immun 1997; 65: 3622-3630.

33. Fisher KJ, Kolesnikow T, Mitchell HM, Wilson JE, O'Rourke $\mathrm{J}$, Lee A. $\operatorname{cag} E$ is essential for gastric colonisation in the Sydney strain mouse model. Gut 1999; 45 Suppl III: A24.

34. Suerbaum S. The complex flagella of gastric Helicobacter species. Trends Microbiol 1995; 3: 168-171.

35. Macnab RM. Genetics and biogenesis of bacterial flagella Annu Rev Genet 1992; 26: 131-158.

36. Minamino T, Macnab RM. Components of the Salmonella flagellar export apparatus and classification of export substrates. J Bacteriol 1999; 181: 1388-1394.

37. Foynes S, Dorrell N, Ward SJ et al. Functional analysis of the roles of FliQ and FlhB in flagellar expression in Helicobacter pylori. FEMS Microbiol Lett 1999; 174: 33-39.

38. Kammler M, Schön C, Hantke K. Characterization of the ferrous iron uptake system of Escherichia coli. J Bacteriol 1993; 175: 6212-6219

39. van Vliet AHM, Wooldridge KG, Ketley JM. Iron-responsive gene regulation in a Campylobacter jejuni fur mutant. J Bacteriol 1998; 180: 5291-5298.

40. Segal ED, Tompkins LS. Identification and characterization of a Helicobacter pylori hemolysin. Infect Agents Dis 1993; 2: $178-182$

41. Drazek ES, Dubois A, Holmes RK et al. Cloning and characterization of hemolytic genes from Helicobacter pylori. Infect Immun 1995; 63: 4345-4349.

42. Scheffer J, König W, Hacker J, Goebel W. Bacterial adherence and hemolysin production from Escherichia coli induces histamine and leukotriene release from various cells. Infect Immun 1985; 50: 271-278.

43. Fan X, Gunasena H, Cheng Z et al. Helicobacter pylori urease binds to class II MHC on gastric epithelial cells and induces their apoptosis. J Immunol 2000; 165: 1918-1924.

44. Zhang ZW, Farthing MJG. Molecular mechanisms of Helicobacter pylori associated gastric carcinogenesis. World $J$ Gastroenterol 1999; 5: 369-374.

45. Ottlecz A, Romero JJ, Hazell SL, Graham DY, Lichtenberger LM. Phospholipase activity of Helicobacter pylori and its inhibition by bismuth salts. Biochemical and biophysical studies. Dig Dis Sci 1993; 38: 2071-2080.

46. Nilius M, Malfertheiner P. Helicobacter pylori enzymes Aliment Pharmacol Therapeut 1996; 10 Suppl 1: 65-71.

47. Eberhart CE, Dubois RN. Eicosanoids and the gastrointestinal tract. Gastroenterology 1995; 109: 285-301.

48. Asante $\mathrm{M}$, Ahmed $\mathrm{H}$, Patel $\mathrm{P}$ et al. Gastric mucosal hydrophobicity in duodenal ulceration: role of Helicobacter pylori infection density and mucus lipids. Gastroenterology 1997; 113: 449-454.

49. Jones AC, Logan RPH, Foynes S, Cockayne A, Wren BW, Penn CW. A flagellar sheath protein of Helicobacter pylori is identical to $\mathrm{HpaA}$, a putative $N$-acetylneuraminyllactose-binding hemagglutinin, but is not an adhesin for AGS cells. $J$ Bacteriol 1997; 179: 5643-5647.

50. Marshall BJ, Barrett LJ, Prakash C, McCallum RW, Guerrant RL. Urea protects Helicobacter (Campylobacter) pylori from 
the bactericidal effect of acid. Gastroenterology 1990; 99 697-702.

51. Hazell SL, Mendz GL. How Helicobacter pylori works: an overview of the metabolism of Helicobacter pylori. Helicobacter 1997; 2: 1-12.

52. Mobley HLT, Hu L-T, Foxall PA. Helicobacter pylori urease: properties and role in pathogenesis. Scand $J$ Gastroenterol
1991; 26 Suppl 187: 39-46.

53. Moran AP. Pathogenic properties of Helicobacter pylori. Scand $J$ Gastroenterol 1996; 31 Suppl 215: 22-31.

54. Lee A, Mitchell H. Basic bacteriology of $H$. pylori colonization factors. In: Hunt RH, Tygat GNT (eds) Basic mechanisms to clinical cure. Dordrecht, Kluwer Academic Publishers. 1994: $59-72$. 